\title{
Diffuse Infiltrative Lymphocytosis Syndrome (DILS)
}

aLevay PF, MSc, MMed(Int) bBotes ME, MBChB

aDepartment of Internal Medicine, Kalafong Hospital, Pretoria

${ }^{\mathrm{b}}$ AIDS Clinic, Kalafong Hospital, Pretoria

Correspondence to: Dr Peter Levay, e-mail: peter.levay@up.ac.za

\begin{abstract}
Diffuse infiltrative lymphocytosis syndrome (DILS) is characterised by a persistent CD8+ lymphocytosis and lymphocytic infiltration of various organs. The reported prevalence varies between $0.85-3 \%$, and appears to be more common in Africans. Patients with DILS tend to have higher $\mathrm{CD4}+$ cell counts and survive longer than those patients without DILS. Most patients present with bilateral parotid gland enlargement and features of the Sicca syndrome. Extraglandular involvement is common with the lungs being the most common site, followed by peripheral neuropathy and liver involvement. DILS is a benign presentation in most patients with few complications. Therapeutic trials are lacking although there are isolated reports of good response to antiretroviral and steroid therapy. With the high incidence of HIV in our population it is likely that DILS is under diagnosed probably due to our ignorance of this disease. Awareness of its various presentations may bring to light undiscovered patients with DILS.
\end{abstract}

(P) This article has been peer reviewed. Full text available at www.safpj.co.za

SA Fam Pract 2008;50(2):42-44

\section{Introduction}

Diffuse infiltrative lymphocytosis syndrome (DILS) is characterised by a persistent $\mathrm{CD} 8^{+}$lymphocytosis and lymphocytic infiltration of various organs. It was first reported in 1989 from New York in a cohort of 12 patients who were HIV positive with parotid gland enlargement, pulmonary insufficiency and lymphadenopathy. ${ }^{1}$

\section{Demographics}

The prevalence in the United States of America (USA) was found to be $3 \%$ (definitive) and $3.4 \%$ (possibly) in an HIV positive outpatient population. ${ }^{2}$ In the largest study to date the prevalence was found to be $0.85 \%$ in an outpatient population of $4100,{ }^{3}$ while in France a prevalence of $2.5 \%$ was noted in a retrospective study. ${ }^{4}$ DILS appears to be more prevalent in Africa than in the USA. ${ }^{5}$ In the latter study, $48 \%$ of HIV positive patients had features of DILS on lymph node biopsy. ${ }^{5}$ It is reported to be more common in African Americans (60\%) than American whites (26\%) ${ }^{3,5}$ The odds ratio for DILS for blacks was found to be as high as 2.32 in comparison to other races. ${ }^{3}$

\section{CD4+ and CD8+ cell count in patients with DILS}

Patients with DILS generally present in an early HIV stage, have higher $\mathrm{CD}^{+}$cell counts (commonly above $200 / \mu \mathrm{l}$ ), with fewer opportunistic infections ${ }^{1,4,6}$ and are found to be less advanced in their HIV clinical stage with longer survival. ${ }^{2,7}$ Some authors however report that up to $37 \%$ of their patients met the Centers for Disease Control and Prevention case definition of AIDS. ${ }^{3}$ There has been no published literature on the $\mathrm{CD} 8^{+}$cell counts in patients with DILS. Our own experience suggests that most of our patients have CD8+ lymphocytosis (counts $>835 / \mu \mathrm{l}$ ) and some $\mathrm{CD} 8^{+}$hyperlymphocytosis

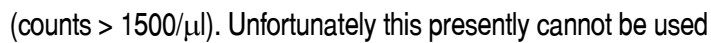

to discriminate between diseases at presentation as $50 \%$ of our population with HIV have increased $\mathrm{CD} 8{ }^{+}$cell counts and $20 \%$ have CD8+ hyperlymphocyctosis (Levay unpublished results).

\section{Presentation}

The most common clinical presentation is asymptomatic salivary gland enlargement, typically bilateral parotid gland involvement, ${ }^{1,3,6,8}$ with features of the Sicca syndrome (xerostomia in $82 \%$ and xerophthalmia 35\%) or Sjogren's-like syndrome. ${ }^{3,9}$ Unilateral parotid gland involvement has been reported although this is a rare finding. ${ }^{9}$ Salivary gland involvement typically is associated with cervical lymphadenopathy, ${ }^{10,11}$ while generalised lymphadenopathy occurs in $80-100 \%$ of patients. ${ }^{4,6}$ DILS can be differentiated from Sjogren's syndrome by the degree of gland enlargement, high occurrence of extraglandular involvement, relative absence of auto antibodies, and differing HLA associations. ${ }^{12}$

The lung is the most common extraglandular site of disease, affecting $31 \%$ of patients in the largest patient group investigated for DILS to date. ${ }^{3}$ Up to $60-71 \%$ had biopsy proven lymphocytic interstitial pneumonitis in smaller studies., ${ }^{4,6}$ Lung involvement may clinically and radiologically mimic Pneumocystis Jiroveci pneumonia. ${ }^{9}$ A radiological picture of an interstitial disease may also be present. ${ }^{13}$ Two of our patients have been misdiagnosed with pulmonary tuberculosis due to the miliary pattern on chest $\mathrm{X}$-rays.

Peripheral neuropathy has been reported with DILS ${ }^{9}$ occurring in approximately $20-25 \%$ of patients, ${ }^{4,6}$ although typical lymphocytic infiltration in nerves has not been demonstrated in all studies. ${ }^{14} \mathrm{All}$ studies and case presentations reported thus far note the presence of the Sicca syndrome in all patients. ${ }^{7}$ The neuropathy presents as either 


\section{Clinical case study 1}

Patient with DILS presenting with paratoid gland enlargement (Figure 1A) and bilateral pulmonary infiltrates predominantly involving the lower lung regions (Figure 1B). After two weeks of steroid therapy she had a dramatic clinical and radiological response (bottom CXR) (Figure 1C). This patient was initially clinically diagnosed with pulmonary tuberculosis at the time of presentation (Figure 1B).

Figure 1A: Parotid gland enlargement

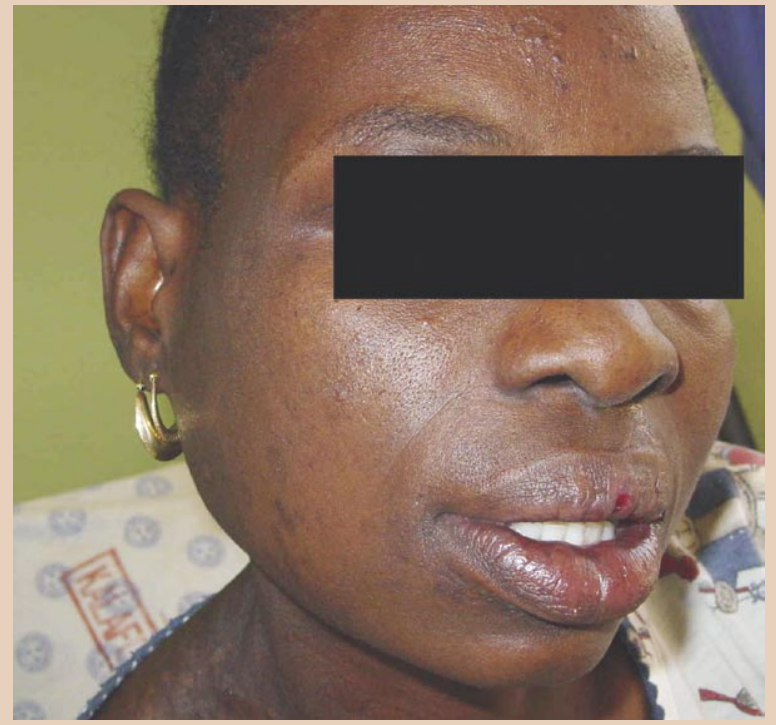

Figure 1B: Bilateral pulmonary infiltrates predominantly involving the lower lung regions.

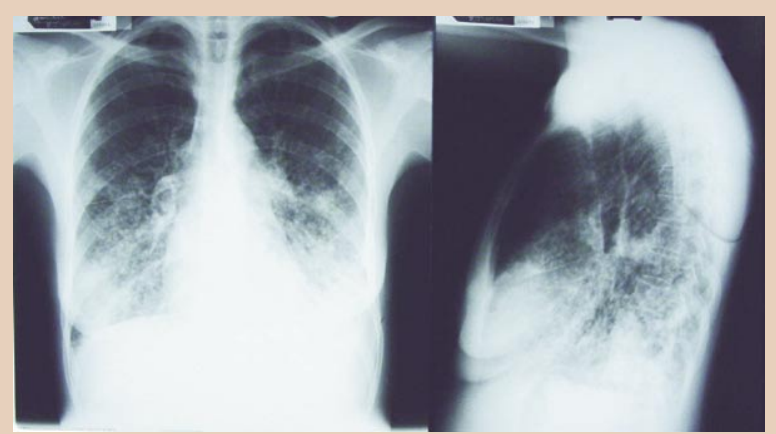

Figure 1C: Dramatic radiological response after two weeks of steroid therapy.

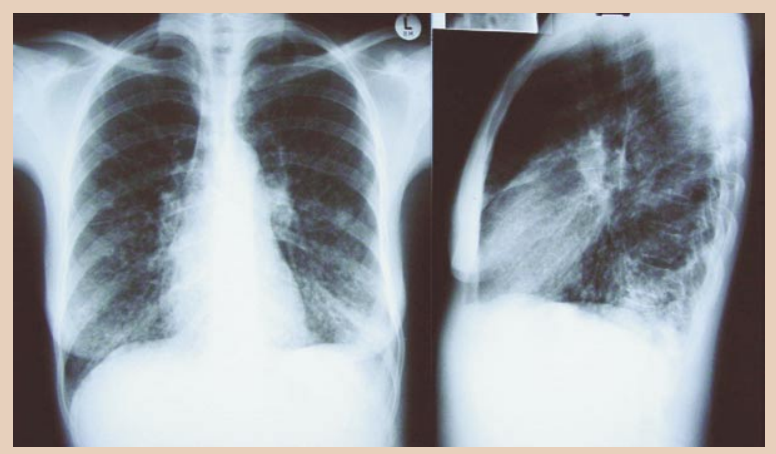

\section{Clinical case study 2}

Patient with DILS presenting with a predominantly interstitial pattern involving lower lung lobes (Figure 2A) with an example of chest CT findings (interstitial, ground glass pattern) (Figure 2B)

Figure 2A: Bilateral interstitial pattern involving lower lung lobes.
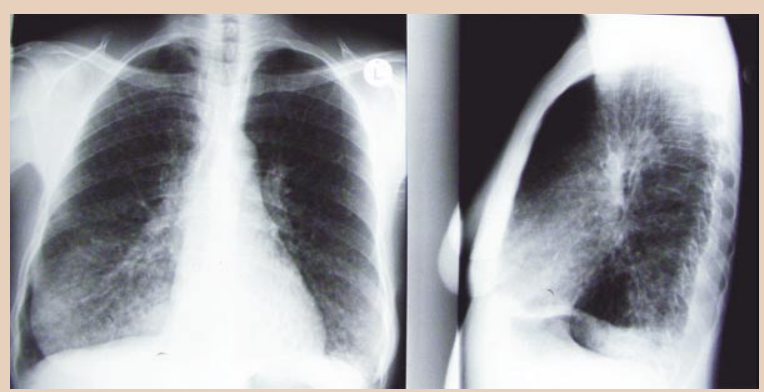

Figure 2B: Chest $\mathrm{CT}$ findings with an interstitial, ground glass pattern

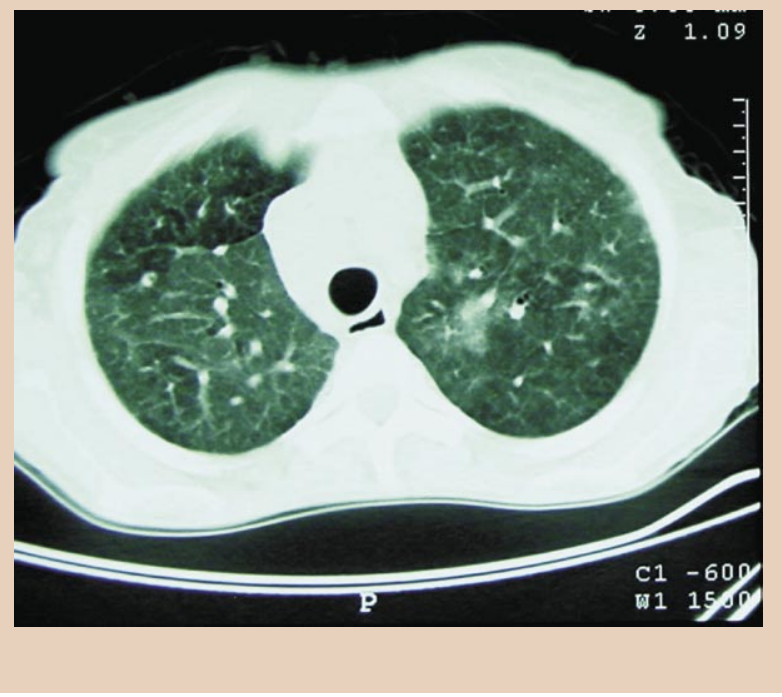

acute or sub-acute, there is always a sensory (painful) component, and most $(67 \%)$ are bilateral. ${ }^{17}$ Electrophysiological studies show an axonal neuropathy in $80 \%$ of patients. ${ }^{7}$

Other less common presentations include liver involvement, which has been reported in up to $23 \%$ of patients with DILS, ${ }^{3}$ and can present with the picture of hepatitis. ${ }^{9}$ Only rarely has it been reported to affect the gastrointestinal tract. ${ }^{6,15} \mathrm{~A}$ single case of splenomegaly has been reported. ${ }^{4}$ Myositis is a common extra-glandular site of involvement, occurring in $26 \%$ of patients in one study. ${ }^{3,9}$ Interstitial nephritis may occur, however this is an uncommon finding. ${ }^{9,16,17} \mathrm{~A}$ single case of bilateral pan-uveitis has also been associated with DILS. ${ }^{18}$

DILS is mostly associated with HIV, although there are isolated case reports of seronegative patients with the syndrome. ${ }^{19}$ A recent study found Ebstein-Barr virus markers in all salivary glands with immunohistochemistry which may substantiate a role for this virus in DILS. ${ }^{8}$ The same study found no evidence for a possible role of cytomegalovirus, as substantiated by other authors. ${ }^{5,8}$

\section{Histology}

Histology generally shows CD8+ lymphocytic infiltration. ${ }^{5}$ Infiltration of the salivary glands is typically periductal, with associated acinar atrophy, ductal ectasia, and mild to moderate fibrosis. ${ }^{8}$ Ductal atypia was found in $96 \%$ of 30 patients with DILS in a West African 
study. ${ }^{5}$ Neuronal involvement shows a marked angiocentric CD8 ${ }^{+}$ infiltrate without mural necrosis with expression of HIV p24 protein in macrophages. ${ }^{7}$

\section{Complications}

Complications of DILS are few. The majority of patients are asymptomatic apart from the Sicca symptoms. There are isolated reports of increased incidence of lymphoma in patients with DILS, although these studies contain very few patients. ${ }^{7}$ The discordance between findings and reported symptoms may be a clue to underlying DILS.

\section{Treatment}

There are no randomised controlled trials that have evaluated therapy for DILS. Isolated reports of successful treatment with Zidovudine (6/6 response) and steroids (5/6) have been noted. ${ }^{7}$ We have had similar findings with our patients. It has been our experience that symptoms tend to decrease with the declining CD4 cell counts (patients not on antiretroviral therapy). Retrospective analysis of an outpatient clinic for HIV positive patients showed there was a significant decrease in the prevalence of DILS with the introduction of highly active antiretroviral therapy. ${ }^{20}$ We could not find any reports of DILS presenting as a component of immune reconstitution.

\section{Conclusions}

Very few reports of DILS have been made from southern Africa. This may be due to a lack of knowledge concerning this disease or that in our population of patients with HIV, DILS may be an uncommon complication or presentation. Our experience at Kalafong Hospital, Pretoria would seem to support the latter, where the majority of our patients are African blacks with a high HIV incidence. Although our patients have a high prevalence of $\mathrm{CD} 8^{+}$lymphocytosis, parotid gland enlargement is an uncommon finding in stark contrast to the presence of lymphadenopathy in our population. Increasing awareness of this apparently rare presentation of HIV may uncover undiagnosed DILS.

\section{References}

1. Itescu S, Brancato LJ, Winchester R. A sicca syndrome in HIV infection: association with HLA-DR5 and CD8 lymphocytosis. Lancet 1989:2:466-8.

2. Williams FM, Cohen PR, Jumshyd J, Reveille JD. Prevalence of the diffuse infiltrative lymphocytosis syndrome among human immunodeficiency virus type 1 positive outpatients. Athritis Rheum 1998;41:863-8.

3. Kazi S, Cohen PR, Williams F, Schempp R, Reveille JD. The diffuse infiltrative lymphocytosis syndrome. Clinical and immunogenetic features in 35 patients. AIDS 1996;10:385-91

4. Malbec D, Pines E, Boudon P, Lusina D, Choudat L. CD8 hyperlymphocytosis syndrome and human immunodeficiency virus infection: 5 cases. Rev Med Interne 1994;15:630-3.

5. McArthur $\mathrm{CP}$, Subtil-DeOliveria $A$, Palmer $\mathrm{D}$, et al. Characteristics of salivary diffuse infiltrative lymphocytosis syndrome in West Africa. Arch Pathol Lab Med 2000;124:1773-9.

6. Itescu S, Brancato LJ, Buxbaum J, et al. A diffuse infiltrative CD8 lymphocytosis syndrome in human immunodeficiency virus (HIV) infection: a host immune response associated with HLA-DR5. Ann Intern Med 1990;112:3-10.

7. Moulignier A, Authier FJ, Baudrimont M, et al. Peripheral neuropathy in human immunodeficiency virus-infected patients with the diffuse infiltrative lymphocytosis syndrome. Ann Neurol 1997;41:438-45.

8. Rivera H, Nikitalis NG, Castillo S, Siavash H, Papadimitriou JC, Sauk JJ. Histopathological analysis and demonstration of EBV and HIV-p2 antigen but not CMV expression in labial minor salivary glands of HIV patients affected by diffuse infiltrative lymphocytosis syndrome. $J$ Oral Pathol Med 2003:32:431-7.

9. Franco-Paredes C, Rebolledo P, Folch E, Hernandez I, del Rio C. Diagnosis of diffuse CD8+ lymphocytosis syndrome in HIV-infected patients. AIDS Read 2002;12:408-13.

10. Patel S, Mandel L. Parotid gland swelling in HIV diffuse infiltrative CD8 lymphocytosis syndrome. N Y State Dent 2001;67:22-3.

11. Mandel L, Hong J. HIV-associated parotid lymphoepithelial cysts. J Am Dent Assoc 1999;130 528-32.

12. Itescu $\mathrm{S}$. Diffuse infiltrative lymphocytosis syndrome in children and adults infected with HIV-1: a model of rheumatic illness caused by acquired viral infection. Am J Reprod Immunol 1992;28:247-50

13. Zuger A. Hyperamylasemia and facial swelling in an HIV-infected man. AIDS Clin Care 1995;7:7-9.

14. Gherardi RK, Chretien F, Delfau-Larue MH, et al. Neuropathy in diffuse infiltrative lymphocytosis syndrome: an HIV neuropathy, not a lymphoma. Neurology 1998;50:1041-4.

15. Itescu $S$, Winchester R. Diffuse infiltrative lymphocytosis syndrome: a disorder occurring in human immunodeficiency virus-1 infection that may present as a sicca syndrome. Rheum Dis Clin North Am 1992;18:683-97.

16. D'Agati V, Appel GB. Renal pathology of human immunodeficiency virus infection. Semin Nephrol 1998;18:406-21

17. Lesprit $P$, Fornairon $S$, Michaut $P$, Nochy D, Idatte JM, Modai J. Renal involvement in the diffuse infiltrative CD8 lymphocytosis syndrome. AIDS 1997;11:262-3

18. Henderson HW, Davidson F, Mitchell SM. Intraocular inflammation and the diffuse infiltrative lymphocytosis syndrome. Am J Opthalmol 1998;126:462-4.

19. Agah $R$, Sockell $M$, Felsovanyi A. Diffuse infiltrative lymphocytosis syndrome in a patient not infected with the human immunodeficiency virus. West J Med 1996;164:266-8.

20. Basu D, Williams FM, Ahn CW, Reveille JD. Changing spectrum of the diffuse infiltrative lymphocytosis syndrome. Arthritis Rheum 2006;55:466-72. 